\title{
Controle de plantas daninhas com diuron em diferentes condições de luz ${ }^{1}$
}

\author{
Weed control in distinct light conditions with diuron
}

\author{
Caio Ferraz de Campos $^{2}$; Hermeson dos Santos Vitorino ${ }^{3}$; Dagoberto Martins ${ }^{4}$
}

Resumo - O objetivo deste estudo foi avaliar o controle de plantas daninhas com o herbicida diuron aplicado em pré e pós-emergência em condição de sombreamento e pleno sol. Foi estudado o efeito proporcionado pelo herbicida diuron na formulação $500 \mathrm{SC}$ nas doses de 3,2 e 4,8 L p.c. ha ${ }^{-1}$ sobre as plantas de Euphorbia heterophylla, Ipomoea grandifolia e Raphanus raphanistrum aplicados em pré-emergência e as mesmas doses aplicadas em pós-emergência foram testadas nas plantas de E. heterophylla, Senna occidentalis e I. grandifolia. Para ambas as formas de aplicação, um conjunto de vasos foi semeado e mantido em condições de pleno sol e outro sob uma malha de polietileno que permitiu que 30\% da radiação solar atingisse os vasos. Tanto para aplicação do diuron em pré como em pós-emergência foram eficientes no controle das plantas daninhas, com ação mais lenta das plantas submetidas ao sombreamento, independentemente da dose utilizada.

Palavras-chaves: herbicida, luminosidade, controle químico

Abstract - This study aimed to evaluate the weed control with the herbicide diuron sprayed in pre- and post-emergence, either under shade or full sun. It was studied the effect of the diuron at in the formulation $500 \mathrm{SC}$ at 3.2 and $4.8 \mathrm{~L} \mathrm{ha}^{-1}$ of the trade product on the plants of Euphorbia heterophylla, Ipomoea grandifolia and Raphanus raphanistrum sprayed in pre-emergence, as well as the same doses sprayed in post-emergence on plants of E. heterophylla, I. grandifolia and Senna occidentalis. For both application times, a set of pots was planted and maintained either under full sun or under a mesh that allowed only $30 \%$ of the radiation to reach the pots. The control levels were considered excellent for both application times; however there was a slower control of plants subjected to shading independent of the dose applied.

Keywords: herbicide, luminosity, chemical control

\footnotetext{
${ }^{1}$ Recebido para publicação em 17/09/2012 e aceito em 18/10/2012.

${ }^{2}$ Engenheiro Agrônomo pela FCA/UNESP (Campus Botucatu, SP), Mestre pela FCA/UNESP de Botucatu, SP. Email: <caio.agro@hotmail.com>. (Autor para correspondência).

${ }^{3}$ Professor Adjunto, UESPI - Campus Professor Barros Araújo, Picos, PI.

${ }^{4}$ Professor Adjunto, FCA/UNESP Botucatu, SP.
} 


\section{Introdução}

A luz por ser fonte primária de energia relacionada à fotossíntese é um dos principais fatores que influenciam o crescimento dos vegetais (Campos \& Uchida, 2002). Os fatores ambientais, em especial, a duração, a intensidade e a distribuição da luz podem ter efeitos substanciais no desenvolvimento, no tamanho e na espessura das folhas (Martins et al., 2009; Terashima \& Hikosaka, 1995). As plantas que crescem sob altas intensidades luminosas podem apresentar cutícula mais espessa do que plantas que crescem na sombra ou em condições de baixa luminosidade e, esta geralmente, apresenta menor resistência à absorção de herbicidas (Silva et al., 2002).

Em culturas perenes como café, cacau, citros, seringueira e uva, assim como, em culturas semi-perenes como a cana-de-açúcar é comum infestações de plantas daninhas dispostas tanto na linha como na entrelinha que estão sujeitas à sombra projetada pela cultura. Para estas culturas é recomendada a utilização do herbicida diuron aplicado em préemergência ou em pós-emergência precoce, nas quais as plantas daninhas devem apresentar de 4 a 6 folhas.

Nas culturas perenes e semi-perenes, assim como nas anuais em sistema plantio direto citadas anteriormente, o não revolvimento do solo promove modificações na dinâmica populacional das plantas daninhas. Esse evento está associado a mudanças na composição da comunidade infestante no tempo, considerando o número e a dominância relativa de cada espécie no agro-ecossistema (Zelaya et al., 1997). Essas modificações envolvem aspectos da biologia e ecologia das espécies e podem ser alteradas pelas condições de manejo do solo, das culturas e dos métodos de controle. Dentre as espécies que comumente infestam essas culturas estão a Euphorbia heterophylla L. (leiteiro), Senna occidentalis (L.) LINK (fedegoso do campo), Ipomoea grandifolia (Dammer) O'Donell (corda-deviola) e Raphanus raphanistrum L. (nabiça).
A E. heterophylla é uma espécie importante por afetar a produtividade de cerca de 30 culturas anuais e perenes em 56 países. Essa planta é nativa de regiões tropicais e subtropicais do continente americano (Holm et al., 1991). O fedegoso é uma planta agressiva, altamente prolifera, de sementes grandes e que apresenta baixa sensibilidade à maioria dos herbicidas recomendados para a cultura da cana-de-açúcar (Lorenzi, 2006; Rodrigues \& Almeida, 2011). As plantas daninhas como leiteiro e fedegoso são importantes infestantes de canaviais, com poucos herbicidas recomendados para seu controle (Rodrigues \& Almeida, 2011). De acordo com Martins et al. (1999), existe um processo crescente de infestação de Ipomoea spp., notadamente em áreas de cana crua. Já a nabiça é uma invasora anual, infestante de diversas culturas agrícolas, frequentemente de inverno, com características morfológicas semelhantes ao nabo forrageiro (Lorenzi, 1991).

O diuron é um inibidor da transferência de elétrons no fotossistema II (PS II) que, segundo Fuerst e Norman (1991), impede a redução da quinona $\mathrm{A}$, por competir com a quinona $\mathrm{B}$ pelo sítio de ligação à proteína $\mathrm{D} 1$, o que ocasiona a saída de QB e, consequentemente, interrupção no fluxo de elétrons, não permitindo com isso a redução do NADPH, a qual é essencial para a fixação de $\mathrm{CO}_{2}$ (Breitenbach et al., 2001). Dessa forma, a intensidade de luz interceptada pela planta pode influenciar o controle de plantas com a utilização desse herbicida.

Diante da relevância do assunto e a falta de abordagem na literatura, objetivou-se com esse estudo avaliar o controle de algumas plantas daninhas através do herbicida diuron aplicado em pré e pós-emergência, em diferentes condições de luminosidade.

\section{Material e Métodos}

O trabalho foi conduzido na Faculdade de Ciências Agronômicas (FCA/UNESP), campus de Botucatu-SP. As plantas daninhas 
estudadas foram: $E$. heterophylla, $S$. occidentalis, I. grandifolia e $R$. raphanistrum. Estas foram semeadas em vasos plásticos de $15 \times 15 \times 15 \mathrm{~cm}$, com um total de 60 sementes para os vasos aplicados em pré-emergência e 10 sementes para os vasos aplicados em pósemergência, baseada no potencial de germinação em função da porcentagem de germinação aferida para cada espécie previamente, sendo que apenas uma planta foi deixada para as aplicações em pós-emergência.

Utilizou-se $\mathrm{o}$ herbicida diuron na formulação $500 \mathrm{SC}$ nas doses de 3,2 e 4,8 L p.c. ha ${ }^{-1}$ sobre as plantas de E. heterophylla, I. grandifolia e $R$. raphanistrum aplicados em pré-emergência e as mesmas doses aplicadas em pós-emergência foram testadas nas plantas de E. heterophylla, $S$. occidentalis e $I$. grandifolia. Para ambas as formas de aplicação um conjunto de vasos foi semeado e mantido em condições de pleno sol (valor médio de fluxo de fótons sinteticamente ativos durante o período experimental: $1.375 \mathrm{mmol} \mathrm{s} \mathrm{m}^{-1}$ ) e outro conjunto sob uma malha de polietileno que permitiu que $30 \%$ da radiação solar atingisse os vasos (valor médio de fluxo de fótons sinteticamente ativos durante o período experimental: $409 \mathrm{mmol} \mathrm{s}^{-1} \mathrm{~m}^{-2}$ ).

Os tratamentos químicos foram aplicados tanto em pré como em pósemergência utilizado-se pulverizador costal, pressurizado a $\mathrm{CO}_{2}$, munido de barra de aplicação com duas pontas de jato plano tipo XR 110.02VS distanciadas $50 \mathrm{~cm}$ entre si, com pressão de trabalho de $200 \mathrm{kPa}$ e, um consumo de calda de $200 \mathrm{~L} \mathrm{ha}^{-1}$.

Quando se estudou o efeito do herbicida aplicado em pré-emergência, houve contagens diárias das plântulas emergidas. Realizou-se também a avaliação visual a cada dois dias, assim que surgiram os primeiros efeitos causados pelo herbicida às plantas daninhas. As notas de controle na avaliação visual foram atribuídas por meio de uma escala percentual de notas, em que zero representava nenhum controle e $100 \%$ controle total das plantas
(SBCPD, 1995). Os parâmetros utilizados para o estabelecimento das notas visuais de controle foram: inibição de crescimento, quantidade e uniformidade das injúrias e capacidade de rebrotas das plantas.

Para o estudo do efeito do herbicida aplicado em pós-emergência nos tratamentos em que as plantas estavam em condições de luz controlada, os vasos foram mantidos desde a semeadura até a última avaliação sob essa condição. Realizaram-se avaliações visuais da mesma forma em que foram atribuídas a notas de controle quando aplicado o herbicida em pré-emergência e na última avaliação realizada aos 14 dias após a aplicação (DAA) foram coletadas as plantas para determinação da massa seca, sendo as plantas levadas para uma estufa com circulação forçada de ar a $60 \pm 2^{\circ} \mathrm{C}$ até atingir massa constante e, em seguida, foi determinada a massa seca das amostras.

Os tratamentos foram instalados no delineamento experimental inteiramente casualizado com quatro repetições. Os resultados de controle das plantas daninhas e acúmulo de massa seca foram analisados estabelecendo-se o intervalo de confiança pelo teste $\mathrm{t}$ a $5 \%$ de probabilidade. Para determinar intervalo, foi utilizada a seguinte equação: $\mathrm{IC}=$ ( $\mathrm{x}$ desvpad $) / \mathrm{raiz} \mathrm{nr}$, em que $\mathrm{IC}=$ intervalo de confiança; $\mathrm{t}=$ valor de $\mathrm{t}$ tabelado, a $10 \%$ de probabilidade; desvpad = desvio-padrão; e raiz $\mathrm{nr}=$ raiz quadrada do número de repetições.

\section{Resultados e Discussão}

O controle de nabiça com as diferentes doses do herbicida diuron e condições de luz foram satisfatórias (Figura 1). A ação herbicida foi observada nas plantas daninhas a partir do nono dia após a aplicação (DAA), nesse período de avaliação não houve diferença entre as doses, no entanto, observou-se maior controle quando as plantas estavam sob maior intensidade de luz, sendo que, aos 11 DAA, as plantas sob $100 \%$ de luz foram eficientemente controladas independente da dose de herbicida utilizada; já quando as plantas estavam sob 
menor intensidade de luz o controle proporcionado pelo herbicida foi inferior no início das avaliações, porém alcançando valores equivalentes a partir dos 15 DAA (Figura 1).

Aos 13 DAA, as plantas de nabiça foram totalmente controladas pelo herbicida diuron em ambas as doses nas condições de pleno sol; quando submetidas a menor intensidade de luz o controle ainda apresentava-se insatisfatório sem haver diferença entre as doses utilizadas. Já, aos 15 DAA, todos os tratamentos proporcionaram $100 \%$ de controle da planta daninha.

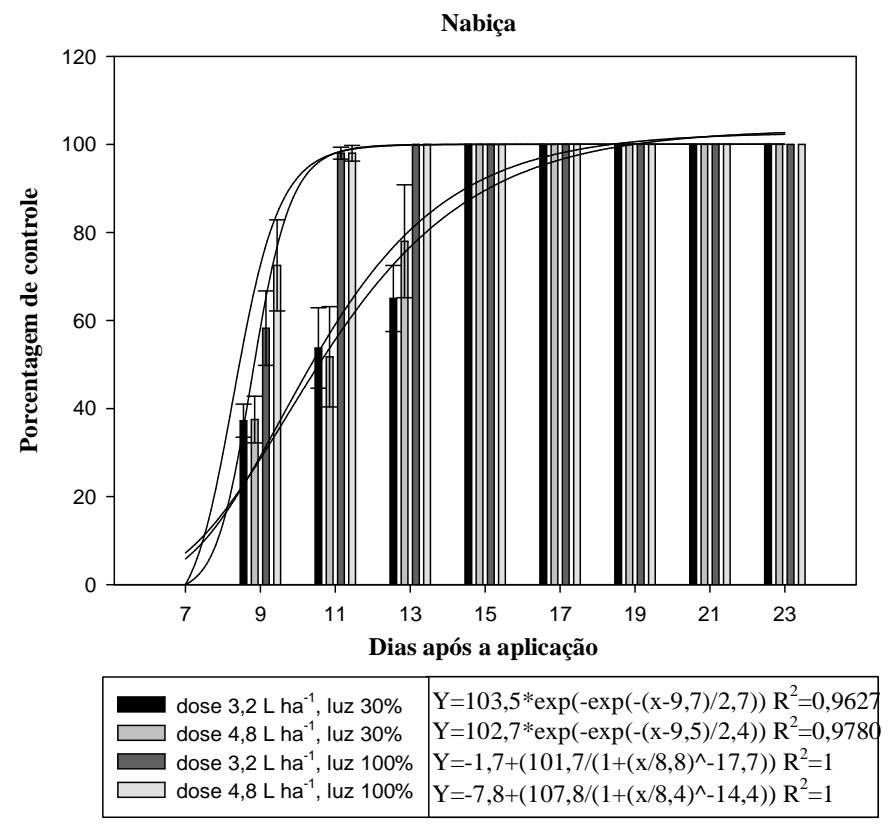

Figura 1. Porcentagem de controle de nabiça (Raphanus raphanistrum) pelo herbicida diuron aplicado em pré-emergência em diferentes períodos de avaliação em função das condições de luz. Botucatu/SP, 2011.

Quando avaliado a eficiência do herbicida para o controle de corda-de-viola observou-se comportamento semelhante aos 9 e 11 DAA no qual o controle proporcionado sobre a planta daninha foi superior quando as plantas foram submetidas à condição de pleno sol (Figura 2). Aos 13 DAA, o melhor controle manteve-se quando não houve redução da luminosidade, entretanto, houve incremento no controle até ao redor de 15 DAA quando as plantas estavam em diferentes condições de luz independente da dose utilizada.

Aos 15 DAA, o controle observado nas plantas de corda-de-viola evoluiu e não se observou diferenças entre as doses. Todavia, os efeitos de fitointoxicação foram muito próximos nas diferentes condições de luz. A partir do $17^{\circ}$ DAA, o controle verificado com as diferentes doses e condições de luz foram semelhantes. 


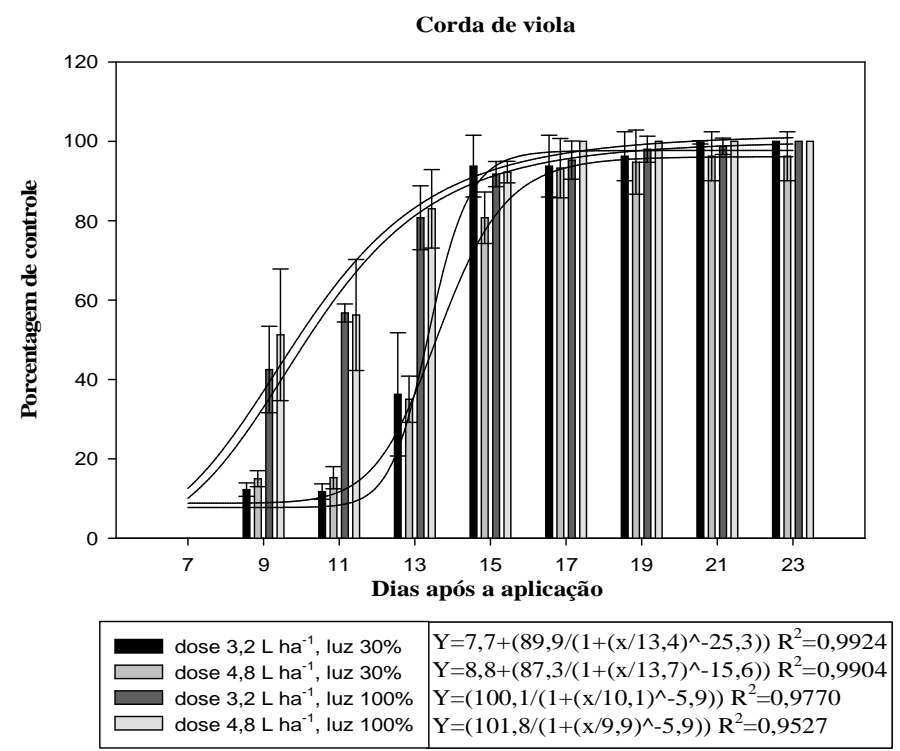

Figura 2. Porcentagem de controle de corda-de-viola (Ipomoea grandifolia) pelo herbicida diuron aplicado em pré-emergência em diferentes períodos de avaliação em função das condições de luz. Botucatu/SP, 2011.

Verificou-se para o leiteiro daninhas estavam em pleno sol o controle foi porcentagem de controle muito próxima para superior, porém não diferiram tanto na menor todos os tratamentos aos 9 e 11 DAA, quanto na maior dose do herbicida. O mesmo entretanto de forma insatisfatória (Figura 3). comportamento foi observado aos 15 e 17 Aos 13 DAA verificou-se pouco incremento no DAA, mas com incremento no controle das controle visual das plantas em condição de luz plantas. reduzida, no entanto quando as plantas

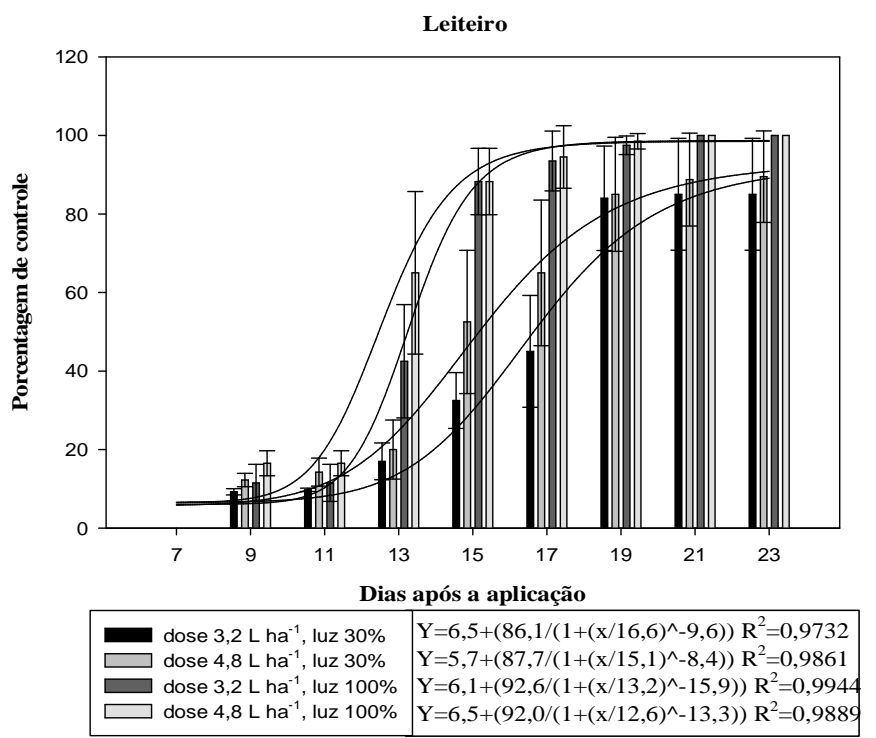

Figura 3. Porcentagem de controle de leiteiro (Euphorbia heterophylla) pelo herbicida diuron aplicado em pré-emergência em diferentes períodos de avaliação em função das condições de luz. Botucatu/SP, 2011. 
Os primeiros trabalhos sugeriam que plantas tratadas com inibidores do FSII eram controladas por "inanição", como resultado da inibição da reação luminosa da fotossíntese. No entanto, plantas tratadas são controladas mais rápido quando expostas a luz do que quando no escuro (Oliveira Jr., 2011).

A partir dos 19 até 23 DAA não houve mais diferença entre o controle proporcionado pelo herbicida diuron nas diferentes doses, assim como nas diferentes condições de luz.
Ressalta-se que aos 21 e 23 DAA apenas as plantas que estavam em condição de pleno sol receberam notas de controle total das plantas de corda-de-viola.

O número máximo de plantas de nabiça emergidas quando estavam em pleno sol foi menor, assim como o efeito do herbicida na redução de plantas ocorreu antecipadamente em relação às plantas submetidas à redução da incidência da luz solar (Figura 4).

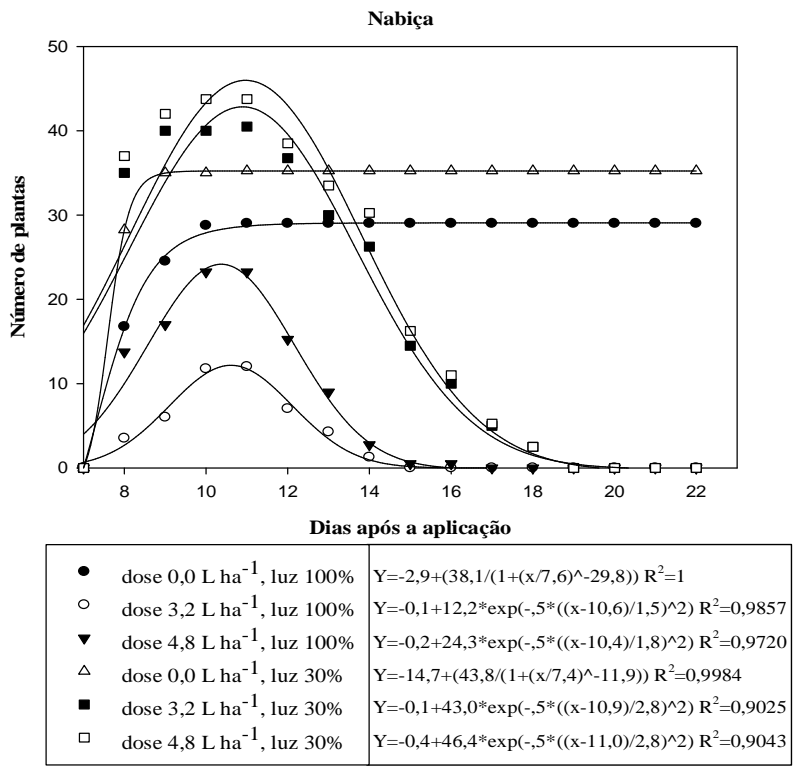

Figura 4. Número de plantas de nabiça (Raphanus raphanistrum) em função das condições de luz e doses do herbicida diuron aplicado em pré-emergência em diferentes períodos de avaliação. Botucatu/SP, 2011.

Com relação à corda-de-viola a redução do número de plantas ocorreu praticamente no mesmo período em ambas as condições de luz estudadas. No entanto, houve menor número de indivíduos quando as plantas estavam em pleno sol (Figura 5).

Para o leiteiro o maior número de plantas emergidas foi observado quando a planta daninha encontrava-se em pleno sol, assim como ocorreu redução no número de plantas emergidas quando as plantas foram submetidas ao sombreamento (Figura 6).

As plantas não são afetadas pelo herbicida diuron até que comessem a fazer fotossíntese. No entanto, o herbicida promove um distúrbio no processo de transferência de elétrons, dessa forma, as moléculas de clorofila continuam captando energia solar e a planta fica com uma carga energética acentuada, sendo denominada clorofila "tripleto", o que ocasiona a formação de radicais livres (Vidal, 1997). Portanto, as plantas que não receberam toda a luz solar provavelmente teve a sua fotossíntese alterada, retardando assim o controle proporcionado pelo herbicida diuron sobre as plantas tratadas. 




Figura 5. Número de plantas de corda-de-viola (Ipomoea grandifolia) em função das condições de luz e doses do herbicida diuron aplicado em pré-emergência em diferentes períodos de avaliação. Botucatu/SP, 2011.


Figura 6. Número de plantas de leiteiro (Euphorbia heterophylla) em função das condições de luz e doses do herbicida diuron aplicado em pré-emergência em diferentes períodos de avaliação. Botucatu/SP, 2011.

O controle em pré-emergência pode estender-ser por um longo período de tempo. Segundo Procópio et al. (2004), a ação do herbicida diuron em pré e pós-emergência inicial é recomendada no controle de gramíneas, folhas largas e perenes de difícil controle e pode ocorrer efeito residual nos solos superior a cem dias.

Quando as plantas foram tratadas com o herbicida diuron aplicado em pós-emergência, observou-se para corda-de-viola, controle superior independente da dose utilizada em 
condição de pleno sol. Dos 6 até aos 10 DAA houve incremento contínuo de controle, sendo que a partir dessa avaliação todos os tratamentos apresentaram excelente eficiência independente da dose utilizada e condição de luz (Figura 7).

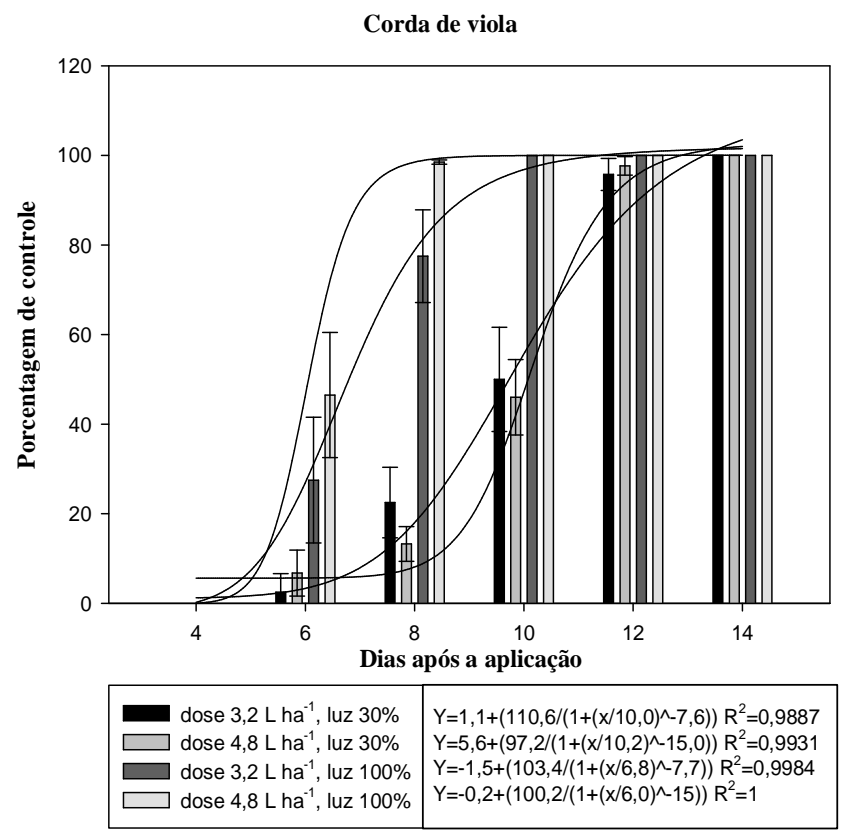

Figura 7. Porcentagem de controle de corda-de-viola (Ipomoea grandifolia) pelo herbicida diuron aplicado em pós-emergência em diferentes períodos de avaliação em função das condições de luz. Botucatu/SP, 2011.

A porcentagem de controle atribuída às plantas de leiteiro aos 6 DAA não diferiu entre todos os tratamentos estudados (Figura 8). Aos 8 e 10 DAA houve incremento no controle das plantas, porém com destaque para o tratamento na maior dose e em condição de pleno sol, com controle mais acentuado que os demais. Aos 12 DAA, não houve diferença entre as doses testadas em luminosidade reduzida. No entanto, em condição de pleno sol, o maior controle ocorreu com o tratamento na maior dose do herbicida diuron.

Aos 14 DAA, todos os tratamentos proporcionaram controle total das plantas daninhas. Ressalta-se que no estudo realizado por Oliveira Jr. et al. (2011) também houve controle satisfatório de leiteiro com o herbicida diuron aplicado em pós-emergência. Segundo os autores, as plantas daninhas tornam-se mais suscetíveis à aplicação em pós-emergência de herbicidas inibidores do fotossistema II quando baixas intensidades luminosas ocorrem durante os dias que precedem a aplicação e quando estas são submetidas à alta intensidade de luz logo após a aplicação.

As plantas de fedegoso não apresentaram sintomas que diferissem os tratamentos utilizados nas avaliações iniciais, aos 6 e 8 DAA. No entanto, o controle apresentado aos 8 DAA foi superior à avaliação anterior (Figura 9). Aos 10 DAA, observou-se controle total das com exceção ao tratamento na menor dose e com luminosidade reduzida. Esse comportamento manteve-se na avaliação seguinte, aos 12 DAA. Aos 14 DAA, observou-se controle total das plantas independente da dose ou luminosidade estudada. 


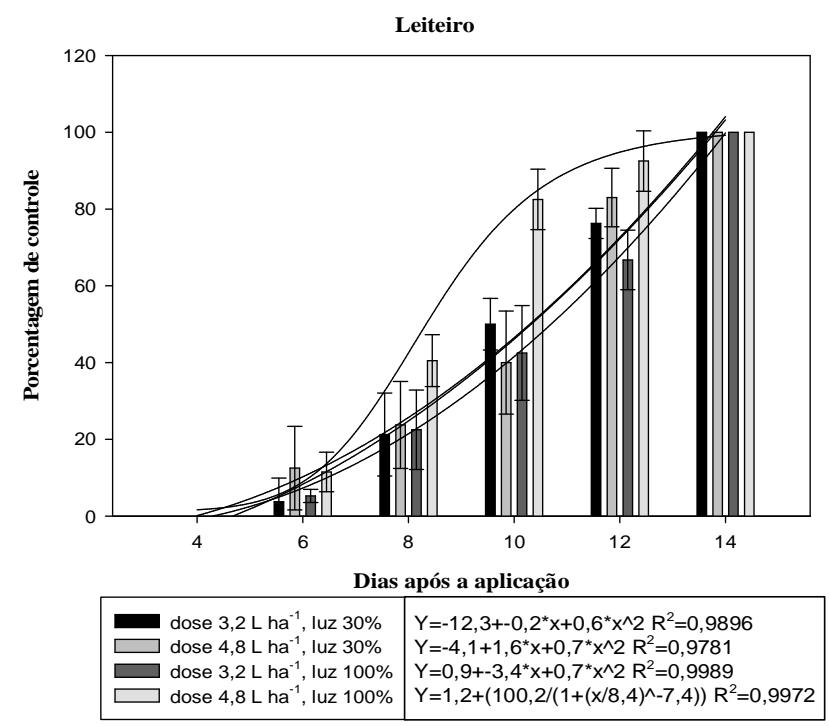

Figura 8. Porcentagem de controle de leiteiro (Euphorbia heterophylla) pelo herbicida diuron aplicado em pós-emergência em diferentes períodos de avaliação em função das condições de luz. Botucatu/SP, 2011.

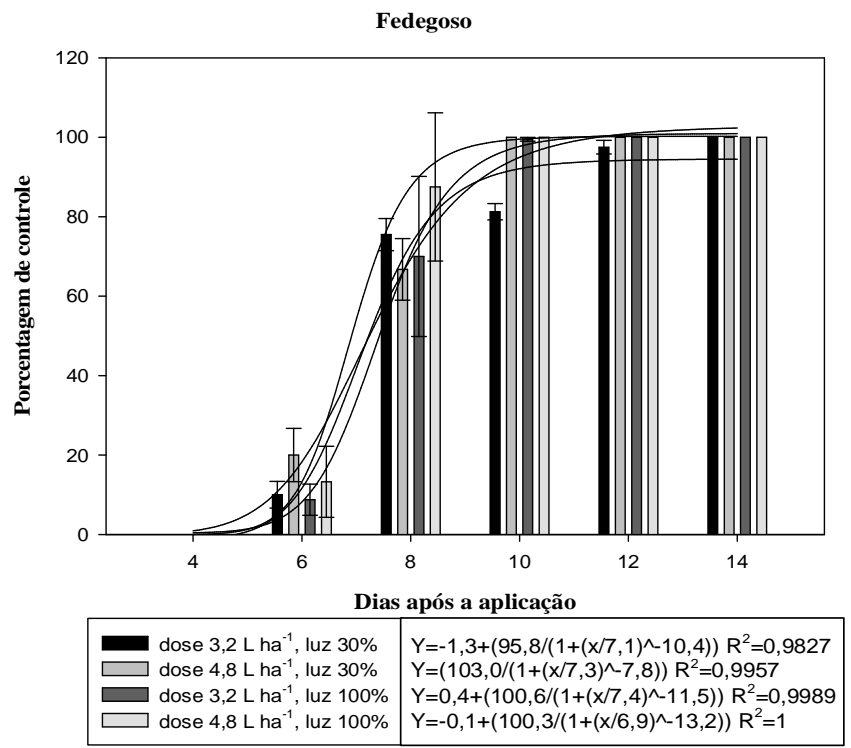

Figura 9. Porcentagem de controle de fedegoso (Senna occidentalis) pelo herbicida diuron aplicado em pré-emergência em diferentes períodos de avaliação em função das condições de luz. Botucatu/SP, 2011.

Quando as plantas foram tratadas com o herbicida diuron na menor dose, manteve-se a tendência de menor acúmulo de massa seca para corda-de-viola e fedegoso mantidas em pleno sol, ao contrário do leiteiro não se observou essa diferença (Figura 10).
$\mathrm{Na}$ maior dose do herbicida, apenas para corda-de-viola mantidas em pleno sol verificou-se o menor acúmulo de massa seca. No entanto, para as demais espécies não foram verificadas diferenças para as duas condições de luz estudadas. 


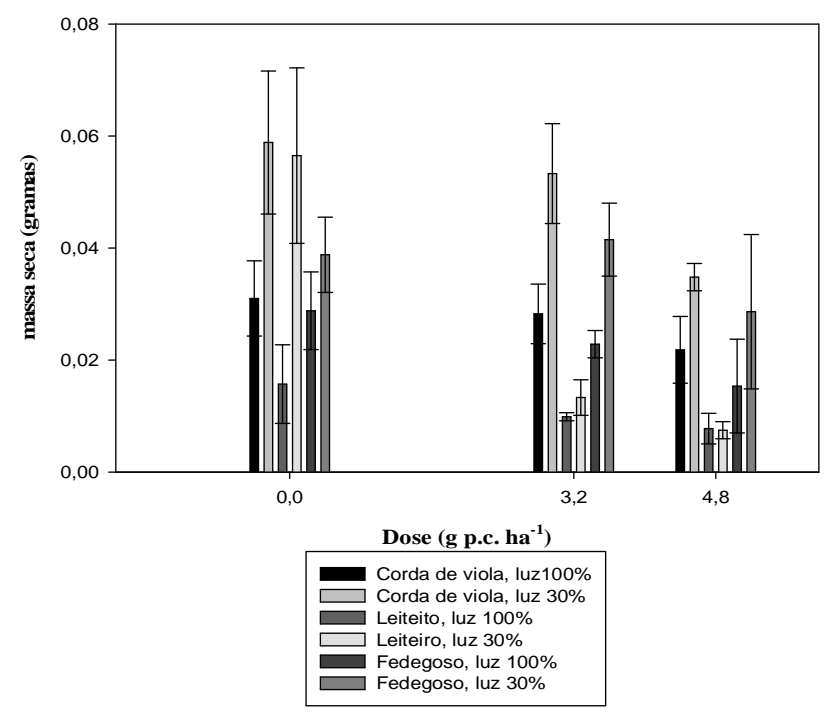

Figura 10. Acúmulo de massa seca das três espécies de plantas daninhas aplicadas em pósemergência com o herbicida diuron em diferentes doses e condições de luz. Botucatu, 2011.

O estudo com a aplicação do herbicida diuron em pós-emergência e pré-emergência, de plantas daninhas pode-se constatar a relação do efeito do herbicida inibidor do fotossistema II com a intensidade de luz, tanto quando absorvido via solo como via foliar.

\section{Conclusões}

$\mathrm{O}$ herbicida diuron proporcionou controle eficiente para Euphorbia heterophylla, Ipomoea grandifolia, Senna occidentalis e Raphanus raphanistrum, tanto para as aplicações em pré como em pós-emergência, com ação mais lenta para quando as plantas foram submetidas ao sombreamento, independentemente da dose utilizada.

\section{Referências}

BREITENBACH, J.; ZHU, C.; SANDMAN, G. Bleaching herbicide norflurazon inhibits phytoene desaturase by competition with the cofactors. Journal of Agriculture and Food Chemical, Davis, v. 49, n. 11, p. 5.270-5.272, 2001.
CAMPOS, M.A.A.; UCHIDA, T. Influência do sombreamento no crescimento de mudas de três espécies amazônicas. Pesquisa Agropecuária Brasileira, Brasilia, v.37, n.3, p.281-288, 2002.

FUERST, E.P.; NORMAN, M.A. Interactions of herbicides with photosynthetic electron transport. Weed Science, Lawrence, v.39, n.3, p.458-464, 1991.

HOLM, L.G. et al. The World's Worst Weeds: ecology and distribution. Malabar: Krieger Publishing Company, 1991. 609p.

LORENZI, H. Plantas daninhas do Brasil: terrestres, aquáticas, parasitas, tóxicas e medicinais. 2.ed. Plantarum: Nova Odessa SP, 1991. 440p.

LORENZI, H. Plantas daninhas do Brasil: terrestres, aquáticas, parasitas, tóxicas e medicinais. 4 ed. Plantarum: Nova Odessa, 2008. 640p.

MARTINS, J. R. et al. Anatomia foliar de plantas de alfavaca-cravo cultivadas sob malhas coloridas. Ciência Rural, Santa Maria, v.39, n.1, p.82-87, 2009. 
OLIVEIRA JR., R.S. et al. Aplicações isoladas ou associadas de diuron, oxyfluorfen e prometryne para o controle de Euphorbia heterophylla. Planta Daninha, Viçosa, v. 29, n. 3, p. 635-645, 2011.

OLIVEIRA JR., R.S. Mecanismo de ação de herbicidas. In: OLIVEIRA Jr., R.S.; CONSTANTIN, J.; INOUE, M.H. (Coord.). Biologia e Manejo de Plantas Daninhas. Curitiba, PR: Omnipax, 2011. p. 141-192.

PROCÓPIO, S. O. et al. Seleção de plantas com potencial para fitorremediação de solos contaminados com o herbicida trifloxysulfuron sodium. Planta Daninha, Viçosa, v. 22, n.2, p. 315-322, 2004.

RODRIGUES, B.N.; ALMEIDA, F.S. Guia de herbicidas. 6.ed. Londrina, 2011. 612p.

SBCPD - SOCIEDADE BRASILEIRA DA CIÊNCIA DAS PLANTAS DANINHAS. Procedimentos para instalação, avaliação e análise de experimentos com herbicidas. Londrina 42 p. 1995.

SILVA, A. A. et al. Biologia e Controle de Plantas Daninhas. Brasília: ABEAS, 2002. $189 \mathrm{p}$.

TERASHIMA, I.; HIKOSAKA, K. Comparative ecophysiology of leaf and canopy photosynthesis. Plant Cell Environment, New Jersey, v.18, n. 10, p. 1.111-1.128, 1995.

VIDAL, R.A. Herbicidas: mecanismos de ação e resistência de plantas. Porto Alegre: R.A. Vidal, 1997. 165p.

ZELAYA, I. A.; OVEN, M. D. K.; PITTY, A. Effect of tillage and environment on weed population dynamics in the dry tropics. Ceiba, Tegucigalpa, v. 38, n. 2, p. 123-135, 1997. 